Supplementary Information

\title{
High speed mass measurement of single metal-organic framework nanocrystal in a Paul trap
}

Caiqiao Xiong, ${ }^{1,2}$ Huihui Liu ${ }^{1,2}$, Yuze $\mathrm{Li}^{1,2}$, Lingwei Meng ${ }^{1,2}$, Jiyun Wang ${ }^{1}$, and Zongxiu Nie ${ }^{1,2 *}$

${ }^{1}$ Beijing National Laboratory for Molecular Sciences, Key Laboratory of Analytical Chemistry for Living Biosystems, Institute of Chemistry, Chinese Academy of Sciences, Beijing 100190 China;

${ }^{2}$ University of Chinese Academy of Sciences, Beijing 100049, China

*E-mail:znie@iccas.ac.cn

SI Experimental methods

Table S1

Figure S1 to Figure S8 


\section{Experimental Methods}

Materials. Resorufin (purity $\geqslant 98 \%$ ) was purchased from Sigma-Aldrich. $3 \mu \mathrm{m}, 1.606$ $\mu \mathrm{m}, 1.013 \mu \mathrm{m}, 493 \mathrm{~nm}$ polystyrene (PS) size standards were purchased from Sigma-Aldrich. $260.3 \mathrm{~nm}$ polystyrene size standards were purchased from Suzhou Nanomicro Technology Company, Ltd. Glucose oxidase (GOx) was purchased from Shanghai Macklin Biochemical Technology Co., Ltd. Zinc acetate dehydrate and 2-methyl imidazole were purchased from Energy Chemical (Shanghai, China). The BCA kit was purchased form Solarbio Life Sciences.

\section{Synthesis and characterization of ZIF-8 crystals and GOx@ZIF-8 composite.}

ZIF-8 nanocrystals was synthesized ${ }^{1-4}$ by adding $0.15 \mathrm{~mL}$ zinc acetate aqueous solution $(0.31 \mathrm{M})$ into $1.5 \mathrm{~mL}$ 2-methyl imidazole aqueous solution $(1.25 \mathrm{M})$. The mixture was stirred at room temperature (about $23{ }^{\circ} \mathrm{C}$ ) for $10 \mathrm{~min}$. Then the product was collected by centrifugation (6000 rpm, $10 \mathrm{~min}$ ), washed two times with deionized water and finally suspended in $300 \mu \mathrm{L}$ deionized water. GOx@ZIF-8 was synthesized in the same way as that for ZIF-8, but in the enzyme solution. Specifically, $0.15 \mathrm{~mL}$ zinc acetate aqueous solution $(0.31 \mathrm{M})$ containing $\mathrm{GOx}(1 \mathrm{mg} / \mathrm{mL})$ was added into 1.5 $\mathrm{mL}$ 2-methyl imidazole aqueous solution (1.25 M). After stirring the mixture at room temperature for $10 \mathrm{~min}$, the product was collected by centrifugation $(6000 \mathrm{rpm}, 10$ min), washed by deionized water for two times, and finally suspended in $300 \mu \mathrm{L}$ deionized water.

The morphology of ZIF-8 and GOx@ZIF-8 was analyzed by a HT-7700 transmission electron microscopy (TEM) operating at $100 \mathrm{kV}$. The size distribution of ZIF-8 and GOx@ZIF-8 was obtained by analyzing their TEM images by Image J software. The number concentrations of ZIF-8 and GOx@ZIF-8 were evaluated by monitoring their transmittance at $595 \mathrm{~nm}^{4}$, and calibrated by using $493 \mathrm{~nm}$ polystyrene size standard with known concentration.

To measure the encapsulating contents of GOx in GOx@ZIF-8, 1.5 mg GOx@ZIF-8 was firstly degraded in $1 \mathrm{~mL}$ acidic water $(\mathrm{pH}=5)$, then the concentration of $\mathrm{GOx}$ was measure by a standard BCA protein assay kit. After $20 \mu \mathrm{L}$ GOx with different concentration $(0.005 \mathrm{mg} / \mathrm{mL}$ to $0.5 \mathrm{mg} / \mathrm{mL}$ ) was incubated with $200 \mu \mathrm{L}$ BCA 
working solution in the 96 well plate at $37^{\circ} \mathrm{C}$ for $30 \mathrm{~min}$, the absorbance at $562 \mathrm{~nm}$ were determined by using Epoch 2 microplate reader (BioTek instrument).

Sample preparation for charge detection quadrupole ion trap mass spectrometry. The $3 \mu \mathrm{m}, 1.606 \mu \mathrm{m}, 1.013 \mu \mathrm{m}, 493 \mathrm{~nm}$ and $260.3 \mathrm{~nm}$ polystyrene (PS) size standards were diluted with deionized water as $10 \mathrm{mg} / \mathrm{mL}, 2.5 \mathrm{mg} / \mathrm{mL}$ $\left(1.1 \times 10^{9}\right.$ particles $\left./ \mathrm{mL}\right), 2 \mathrm{mg} / \mathrm{mL}\left(3.5 \times 10^{9}\right.$ particles $\left./ \mathrm{mL}\right), 1 \mathrm{mg} / \mathrm{mL}\left(1.6 \times 10^{10}\right.$ particles $/ \mathrm{mL})$ and $1 \mathrm{mg} / \mathrm{mL}\left(1.0 \times 10^{11}\right.$ particles $\left./ \mathrm{mL}\right)$, respectively. Resorufin was dispersed in acetonitrile at a concentration of $2 \mathrm{mg} / \mathrm{ml}$, and used as a matrix for achieving the desorption/ionization of particles by using visible-wavelength matrix-assisted laser desorption/ionization (MALDI) method. To prepare the sample for MS analysis, $5 \mu \mathrm{L}$ resorufin solution was first deposited on a glass sample plate and air- dried to form a thin layer of matrix crystal. Then the mixture of target particles $(5 \mu \mathrm{L})$ and probe particles $(3 \mu \mathrm{m}$ polystyrene particles, $5 \mu \mathrm{L})$ were dropped on the top of matrix layer at twice, and air-dried again.

Table S1 Summarization of the information of PS particles

\begin{tabular}{|c|c|c|c|c|c|c|}
\hline \multirow{2}{*}{$\begin{array}{l}\text { Size of PS } \\
\text { particles }\end{array}$} & \multirow{2}{*}{$\begin{array}{l}c\left(10^{9}\right. \\
/ \mathbf{m L})\end{array}$} & \multirow{2}{*}{$\begin{array}{c}\text { Certified mass } \\
\text { (Da) }\end{array}$} & \multicolumn{2}{|c|}{ Mean $q_{\mathrm{eject}}$} & \multirow{2}{*}{$\operatorname{Mean} Z_{\mathrm{t}}^{\mathrm{a}}$} & \multirow{2}{*}{$\begin{array}{c}\text { Determined mass } \\
\text { (Da) }\end{array}$} \\
\hline & & & $q_{\text {eject1 }}$ & $q_{\text {eject2 }}$ & & \\
\hline $260 \mathrm{~nm}$ & 103.2 & $5.84 \times 10^{9}$ & 0.07467 & 0.09014 & $9 \pm 2$ & - \\
\hline $493 \mathrm{~nm}$ & 15.9 & $3.97 \times 10^{10}$ & 0.07753 & 0.09672 & $60 \pm 10$ & $4.33 \times 10^{10}$ \\
\hline $1.013 \mu \mathrm{m}$ & 3.5 & $3.44 \times 10^{11}$ & 0.07794 & 0.1041 & $527 \pm 98$ & $3.70 \times 10^{11}$ \\
\hline $1.606 \mu \mathrm{m}$ & 1.1 & $1.37 \times 10^{12}$ & 0.07863 & 0.11233 & $2229 \pm 408$ & $1.37 \times 10^{12}$ \\
\hline
\end{tabular}

a, $Z_{t}$ was calculated by using eq(5) and the corresponding certified mass. Its value is shown as the mean \pm SD (n is about 200) In this work, only nanoparticles which simultaneously ejected with the probe microparticles were detected. For instance, for $260 \mathrm{~nm}$ polystyrene (PS) particles with charge states $Z \sim 9$ were co-ejected with the probe $3 \mu \mathrm{m}$ PS particles and were detected by the charge detector; however, larger charge states, $Z>11$, which were ejected alone, were undetectable by the charge detector. 
Probe microparticles

- Nanoparticles
Scan direction of $q$

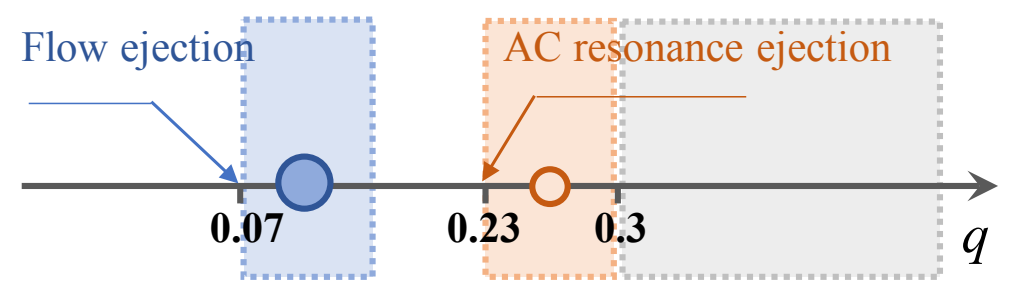

Simultaneous ejection Nanoparticle Only Nanoparticle Detectable Undetectable

Figure S1. Schematic of the probe CD-QIT MS method for mass measurement of nanoparticles by using probe microparticles.

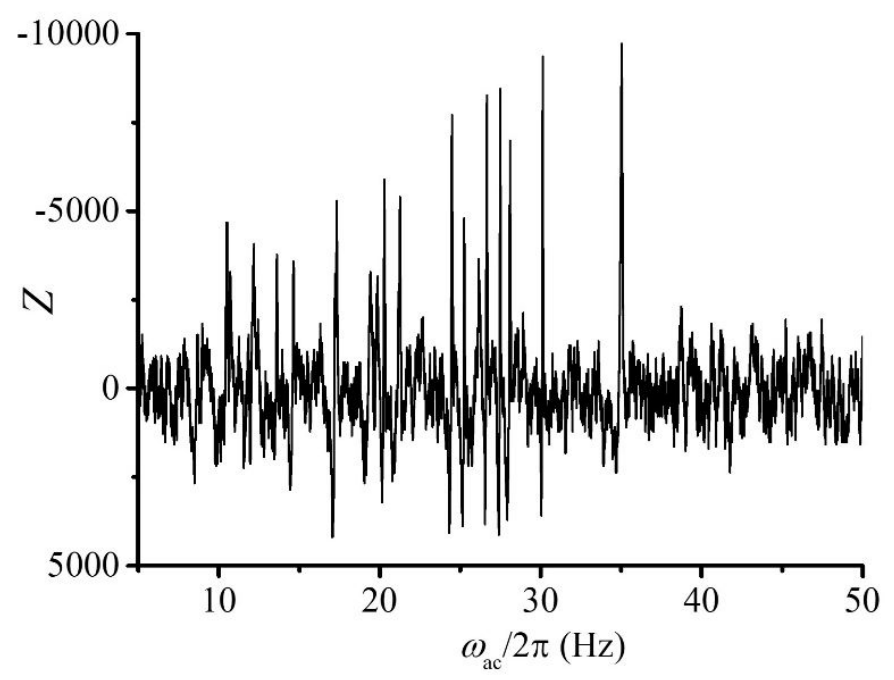

Figure S2. The mass spectrum of $3 \mu \mathrm{m}$ PS particles obtained by scanning the frequency $\omega_{\mathrm{ac}}$ of small ac voltage applied on the lower end cap electrode of QIT. 


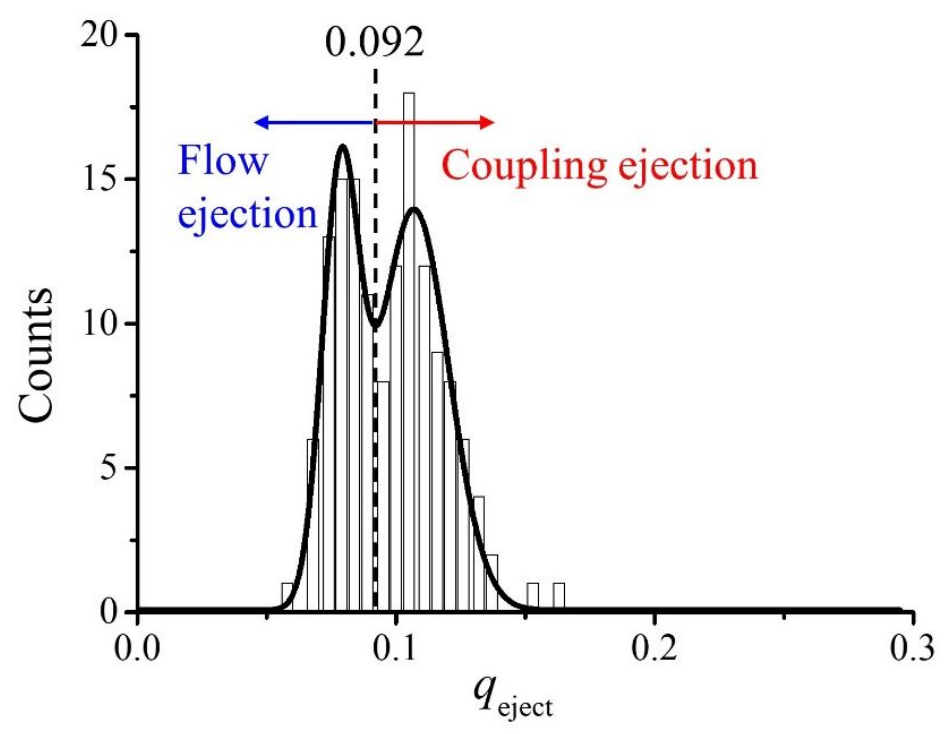

Figure S3. The the cumulative fit $q_{\text {eject }}$ profile of the mixture of $3 \mu \mathrm{m}$ PS and $1.6 \mu \mathrm{m}$ PS particles

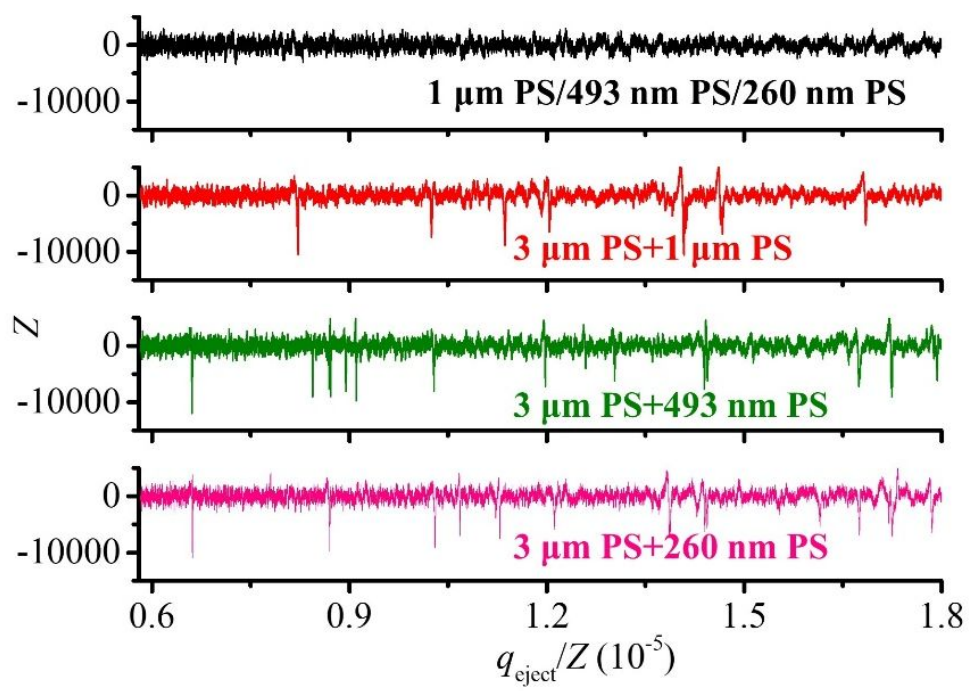

Figure S4. The typical single scan spectra of $1 \mu \mathrm{m}$ PS/493 nm PS/260 nm PS and their mixture with $3 \mu \mathrm{m}$ PS probe particles obtained by scanning RF frequency from 600 $\mathrm{Hz}$ to $1200 \mathrm{~Hz}$ (RF voltage: $800 \mathrm{~V}_{0-\mathrm{p}}$, ac voltage: $5 \mathrm{~V}_{0-\mathrm{p}}$, ac frequency: $50 \mathrm{~Hz}$ ) 


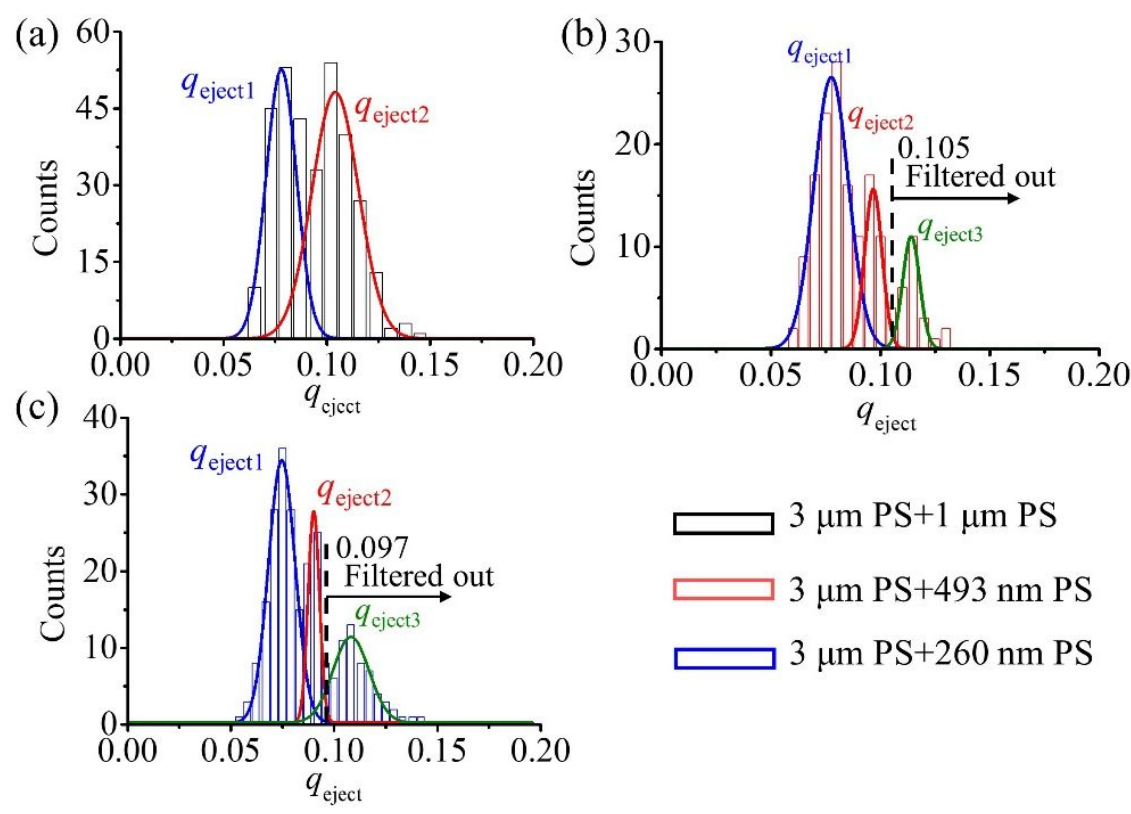

Figure S5. The $q_{\text {eject }}$ histograms of the mixture of $3 \mu \mathrm{m}$ PS particles and $1 \mu \mathrm{m}$ PS particles (a), the mixture of $3 \mu \mathrm{m}$ PS particles and $493 \mathrm{~nm}$ PS particles (b), and the mixture of $3 \mu \mathrm{m}$ PS particles and $260 \mathrm{~nm}$ PS particles (c). The $q_{\text {eject3 }}$ profile with $q_{\text {eject }}>0.1$ was filtered out to eliminate the influence of particle clusters
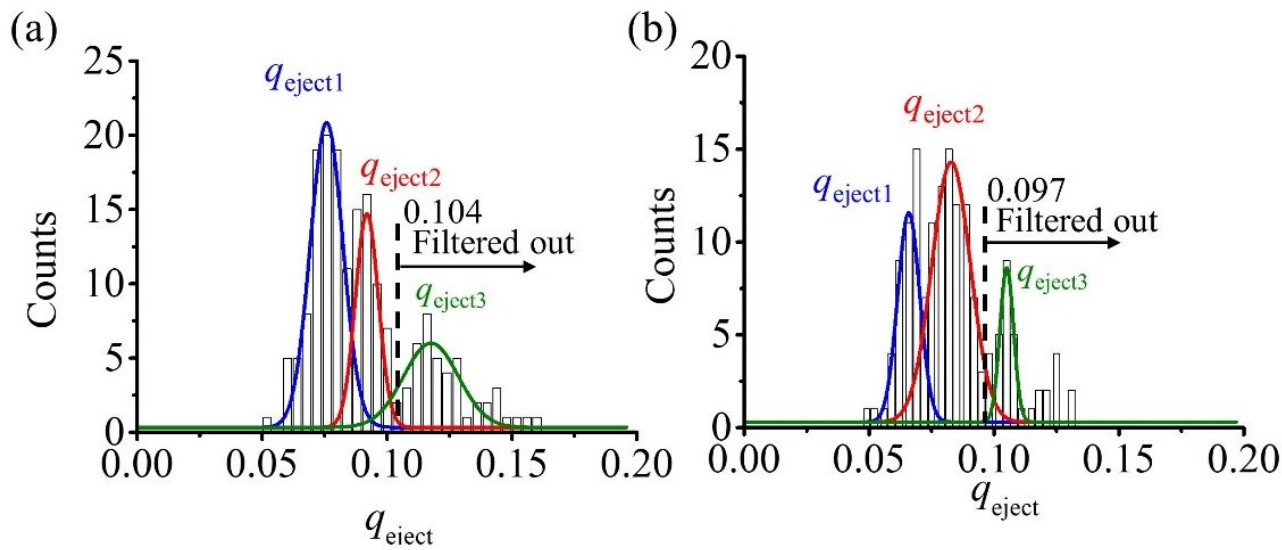

Figure S6. The $q_{\text {eject }}$ histograms of the mixture of $3 \mu \mathrm{m}$ PS particles and ZIF-8 (a) and the mixture of $3 \mu \mathrm{m}$ PS particles and GOx@ZIF-8 (b). The $q_{\text {eject3 profile with }}$ $q_{\text {eject }}>0.1$ was filtered out to eliminate the influence of particle clusters 


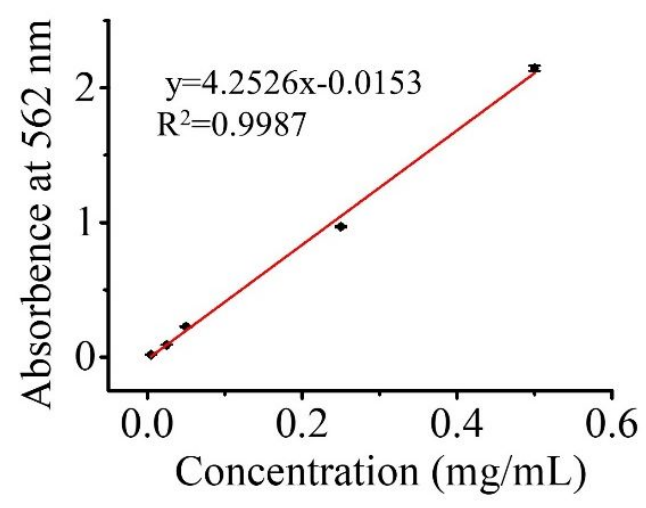

Figure S7. Linear relationship between the absorbance intensity at $562 \mathrm{~nm}$ and GOx concentration obtained in BCA protein assay. Error bars represent the standard deviations of replicate measurements with $n=5$.
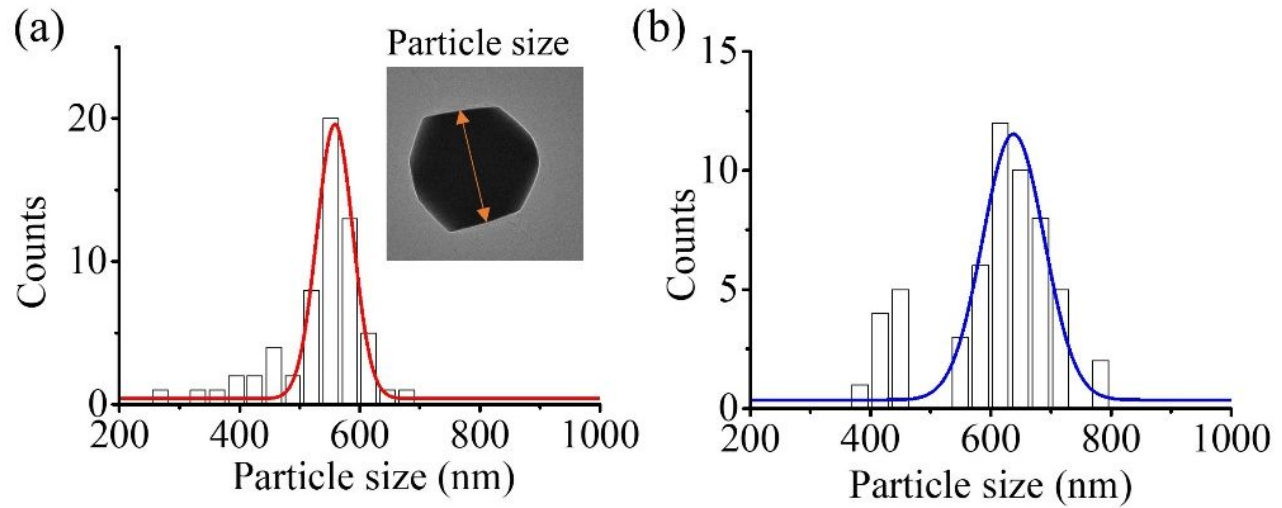

Figure S8. The size distributions ZIF-8 (a) and GOx@ZIF-8 (b) observed by TEM. The diameter of inscribed sphere as shown in the inset of (a) was read by Image $J$ software. 


\section{References}

1. Zhang, Z.; Li, J.; Ji, M.; Liu, Y.; Wang, N.; Zhang, X.; Zhang, S.; Ji, X., Encapsulation of multiple enzymes in a metal-organic framework with enhanced electro-enzymatic reduction of $\mathrm{CO} 2$ to methanol. Green Chemistry 2021, 23 (6), 2362-2371.

2. Wu, X. L.; Yang, C.; Ge, J.; Liu, Z., Polydopamine tethered enzyme/metal-organic framework composites with high stability and reusability. Nanoscale 2015, 7 (45), 18883-18886.

3. Chen, W. H.; Vazquez-Gonzalez, M.; Zoabi, A.; Abu-Reziq, R.; Willner, I., Biocatalytic cascades driven by enzymes encapsulated in metal-organic framework nanoparticles. Nat Catal 2018, 1 (9), 689-695.

4. Chen, G. S.; Kou, X. X.; Huang, S. M.; Tong, L. J.; Shen, Y. J.; Zhu, W. S.; Zhu, F.; Ouyang, G. F., Modulating the Biofunctionality of Metal-Organic Framework-Encapsulated Enzymes through Controllable Embedding Patterns. Angew Chem Int Edit 2020, 59 (7), 2867-2874. 